\title{
Inflammatory bowel disease amid the COVID-19 pandemic: impact, management strategies, and lessons learned
}

\author{
Mahesh Gajendran ${ }^{a}$, Abhilash Perisettit, Muhammad Azizc, Saikiran Raghavapuram d, Pardeep Bansale, \\ Benjamin Tharian', Hemant Goyal ${ }^{\mathfrak{f}}$
}

Paul L. Foster School of Medicine, Texas Tech University Health Sciences Center El Paso, TX; University of Arkansas for Medical Sciences, Little Rock, USA; University of Toledo, OH; OSF St Anthony's Health center, Illinois; Moses Taylor Hospital and Reginal Hospital of Scranton, PA; The Wright Center for Graduate Medical Education, Scranton, PA, USA

\section{Abstract}

\begin{abstract}
The current outbreak of COVID-19 pandemic caused by SARS-CoV-2 has affected nearly 188 countries. Patients with severe COVID-19 are more commonly elderly and suffer from comorbidities such as hypertension, diabetes mellitus, coronary artery disease, chronic pulmonary disease, obesity, and cancer. Inflammatory bowel disease (IBD) affects as many as 6.8 million people globally, and a significant proportion of them are treated with immunosuppressants. Hence, there is an ongoing concern over the impact of COVID-19 on IBD patients and their susceptibility to it. So far, there are about 1439 IBD patients in the Surveillance Epidemiology of Coronavirus under Research Exclusion (SECURE-IBD) registry reported to be infected with SARS-CoV-2. There are many unique challenges and dilemmas that need to be taken into account when managing an IBD patient with COVID-19. The management of each patient should be individualized. The IBD societies and experts have strongly recommended that patients should not discontinue their IBD medications. If the patients have symptoms of COVID-19 or IBD flare-up, they are recommended to call their IBD physician first to discuss their medication. In addition, IBD patients are urged to practice social distancing strictly to minimize the chances of infection. As COVID-19 is rapidly evolving, our experience and understanding of its impact on the IBD population may potentially change in the near future.
\end{abstract}

Keywords COVID-19, SARS-CoV-2, inflammatory bowel disease, Crohn's disease, ulcerative colitis Ann Gastroenterol 2020; 33 (6): 1-12

\section{Introduction}

The current COVID-19 pandemic, caused by SARS-CoV-2, has affected nearly 185 countries. This outbreak started as an epidemic in Wuhan, China, and has now spread globally. As of July 21, 2020, there were more than 14.7 million confirmed cases

aPaul L. Foster School of Medicine, Texas Tech University Health Sciences Center El Paso, TX (Mahesh Gajendran); bDepartment of Gastroenterology and Hepatology, University of Arkansas for Medical Sciences, Little Rock, AR (Abhilash Perisetti, Benjamin Tharian); 'Department of Internal Medicine, University of Toledo, OH (Muhammad Aziz); 'OSF St Anthony’s Health center, Illinois (Saikiran Raghavapuram); e'Division of Gastroenterology, Moses Taylor Hospital and Reginal

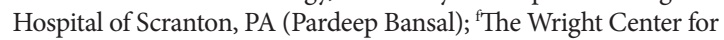
Graduate Medical Education, Scranton, PA (Hemant Goyal), USA

Conflict of Interest: None

Correspondence to: Hemant Goyal, MD FACP PGDCA (MBA), The Wright Center for Graduate Medical Education, 501 S. Washington Avenue, Scranton, PA 18505, USA, e-mail: doc.hemant@yahoo.com

Received 18 June 2020; accepted 22 July 2020; published online 12 October 2020

DOI: https://doi.org/10.20524/aog.2020.0547 worldwide (Fig. 1), with a case fatality rate of 3.64\% [1]. The United States (US) has now become the worst affected country in the world, with more than 2 million reported cases and a case fatality rate of $5.5 \%$ [1]. The data suggest that older adults aged more than 65 years and those with underlying comorbid conditions have a greater risk of severe COVID-19 [2-7].

Inflammatory bowel disease (IBD) is a chronic relapsing inflammatory disorder of the gastrointestinal (GI) tract that comprises 2 major forms: ulcerative colitis (UC) and Crohn's disease $(\mathrm{CD})$. In this article, we aim to provide an overview of the implications of the COVID-19 pandemic for IBD patients and outline the available guidance for their management. There has been a proactive approach from several international IBD and GI societies, issuing recommendations to minimize the risk of SARS-CoV-2 infection and provide support to IBD patients. Some of these measures include the issuance of expert recommendations for managing patients with IBD during the COVID-19 outbreak, postponement of elective endoscopy and surgeries, provision of personal protective equipment (PPE), and availability of online consultancy by IBD specialists.

The global prevalence of IBD was estimated to be 6.8 million in 2017, with an increase over the last 2 decades [8]. IBD is most commonly diagnosed between the ages of 20 

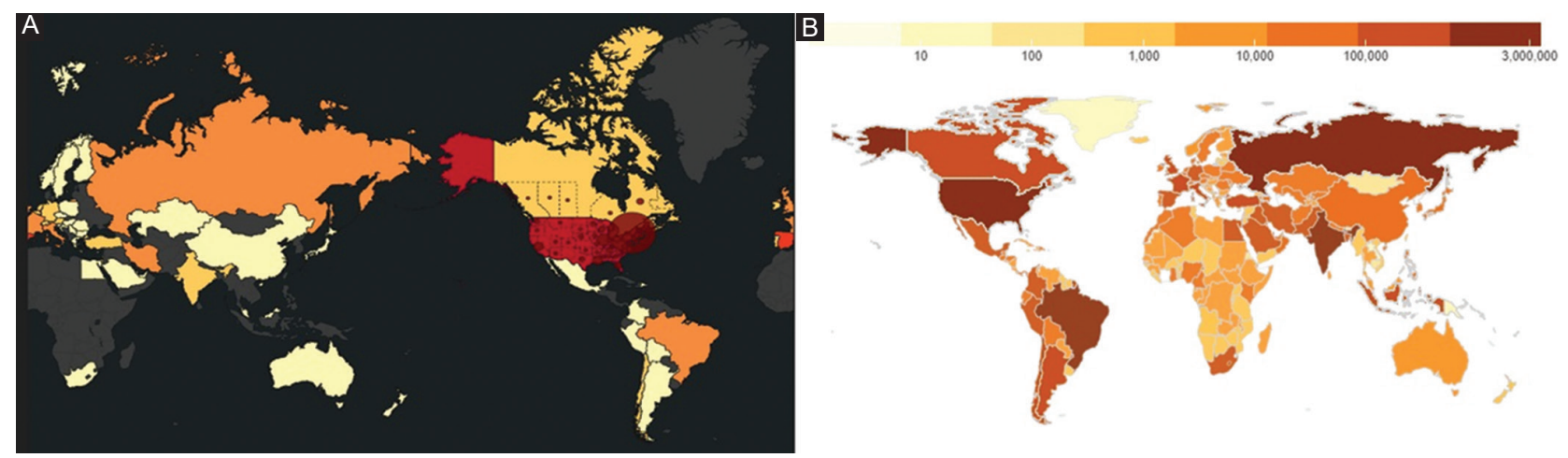

Figure 1 (A) World map of reported cases of COVID-19 infection among patients with inflammatory bowel disease as of July 21, 2020 (reproduced from Johns Hopkins coronavirus resource center [1]), (B) World map of the cumulative number of global COVID-19 cases as of July 21, 2020 (reproduced from SECURE-IBD database [54])

SECURE, Surveillance Epidemiology of Coronavirus under Research Exclusion; IBD, inflammatory bowel disease

and 40 , and the majority of IBD patients are in the workingage group [9-11]. IBD patients are known to make greater use of outpatient services, hospital services, endoscopic and surgical services compared with non-IBD controls [12]. Furthermore, a significant proportion of IBD patients are treated with immunosuppressive medications. Hence, there is ongoing concern about the susceptibility of IBD patients to SARS-CoV-2 infection and its impact on them. According to a recent study from northern California, IBD patients did not have a higher rate of SARS-CoV-2 positivity compared with the general population [13]. IBD patients are more frequently assessed with both esophagogastroduodenoscopies (EGDs) and ileocolonoscopies compared with the non-IBD population [14]. The identification of SARS-CoV-2 RNA in the stool of patients with COVID-19 has raised concerns about possible fecal-oral transmission [15-17]. Furthermore, EGDs pose an increased risk of transmission to healthcare workers, due to their increased exposure to air droplets and saliva during the procedure.

Patients with IBD have a similar life expectancy to the general population, but infections are overrepresented as a cause of death in the IBD patient population [11,18]. Most of these infection-related deaths in IBD patients are related to the complications of severe underlying IBD itself, such as intra-abdominal sepsis, but non-disease-related infections are also responsible for a significant number of deaths [19]. In a large retrospective database-based study of 140,480 patients with IBD and non-IBD controls, IBD patients had a 1.5 times greater risk of influenza infection compared with non-IBD patients (95\% confidence interval [CI] 1.49-1.63) [20]. In that study, the use of corticosteroids was found to be independently associated with an increased risk of influenza (odds ratio [OR] 1.22 , 95\%CI 1.08-1.38) [20].

\section{Structure and transmission of SARS-CoV-2}

SARS-CoV-2 is a positive-sense ribonucleic acid (RNA) virus that consists of a nucleocapsid core with nucleoprotein
(N) and 3 membrane proteins: spike glycoprotein (S), membrane protein $(\mathrm{M})$, and envelope small membrane protein (E) [21]. The viral surface membrane proteins facilitate embedding in the cell membrane of host cells, and $\mathrm{N}$ proteins play an essential role in replication and RNA packaging [22]. Angiotensin-converting enzyme 2 (ACE2) has been identified as the receptor for SARS-CoV-2 to enter epithelial cells, in a similar fashion to SARS-CoV-1 [23].

SARS-CoV-2 is mainly spread through direct exposure (droplet, person to person), and it is also presumed to spread through indirect contact (contaminated objects, airborne transmission) [15]. A recent study found that SARS-CoV-2 was viable and infectious in aerosols for 3 or more hours and on surfaces for up to 2 days [24]. It is essential to consider the potential transmission via aerosol when performing aerosolgenerating procedures such as EGD, endotracheal intubation, noninvasive ventilation, bag-valve-mask ventilation, the suction of GI secretions, nebulizer treatment and insertion of a nasogastric tube. In a study by Xiao et al, SARS-CoV-2 RNA was detected in the stool in $53 \%$ of the patients hospitalized with COVID-19, raising concerns about potential fecal-oral transmission [17].

\section{SARS-CoV-2 in the GI tract}

In humans, the ACE2 receptor is highly expressed in the GI system, including the upper esophagus, duodenum, jejunum, ileum, and colon [14,23]. The ACE2 surface receptor directly interacts with the spike glycoprotein (S protein) of the coronavirus, which results in the entry of the virus into the cells (Fig. 2) and induces the reproduction of new virions intracellularly $[25,26]$. Hence, the detection of viral RNA in the feces suggests that the infectious virions are secreted from the virus-infected GI cells [17]. It is still uncertain whether the presence of active bowel inflammation would increase the risk of SARS-CoV-2 infection. In a study by Wang et al (preprint), RNA sequencing data from the patients with IBD showed that ACE2 expression in the colonocytes was positively associated with 


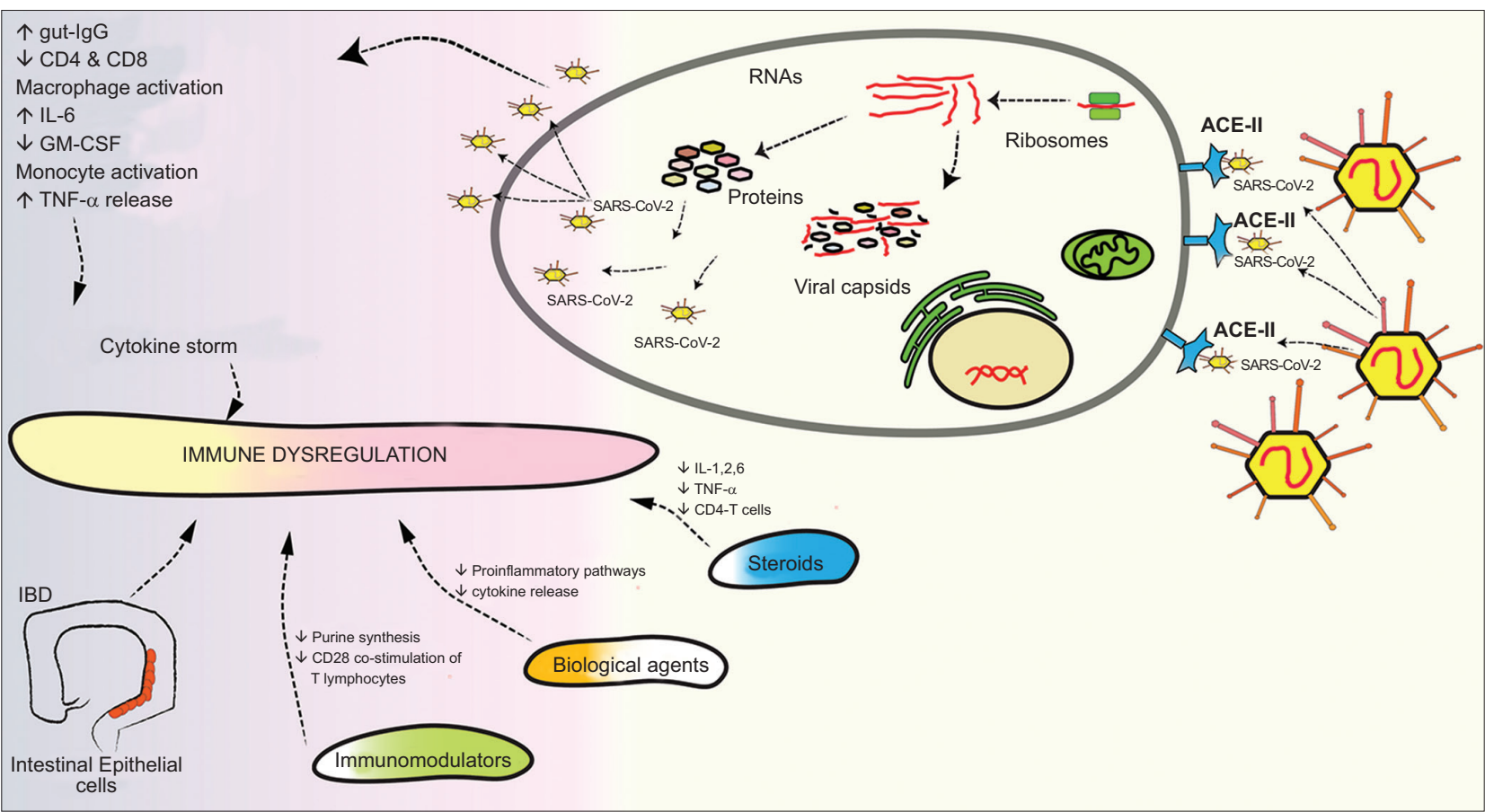

Figure 2 IBD and COVID-19: Infection and putative mechanisms

Schematic representation of SARS-CoV-2 entering gastrointestinal epithelial cells, followed by the development of RNAs and protein. This results in viral capsid formation and the production of multiple new viruses. These viruses enter the bloodstream and release multiple cytokines (storm), thus contributing to immune dysregulation, a predominant component of IBD

SARS-CoV-2, severe acute respiratory distress coronavirus 2; ACE-II, angiotensin-converting enzyme II; RNA, ribonucleic acid; IgG-immunoglobulin G; IL-6, interleukin 6; GM-CSF, granulocyte colony-stimulating factor; IBD, inflammatory bowel disease

viral entry, but negatively associated with viral transcription and protein translation [27]. Hence, the authors concluded that ACE2 expression might play a dual role in mediating the susceptibility and immunity to SARS-CoV-2 infection [27].

The overall detection rate of SARS-CoV-2 RNA in stool specimens has been reported to be in the range of 53$55 \%[16,17]$. A recent study by Zhao et al showed that about $44 \%$ of COVID-19 patients had positive rectal swabs for SARS-CoV-2 RNA at 1 week after illness onset, which decreased in weeks 2-7 to $30 \%, 16.7 \%, 12.3 \%, 12.3 \%, 5.2 \%$, and $0.8 \%$ respectively [28]. The authors also observed that the SARS-CoV-2 RNA in fecal samples remained for an unexpected longer duration of time at a higher viral load than the paired respiratory samples [28].

The duration of positive stool ranges from 1 to 43 days, and more than $20 \%$ of patients have positive stool RNA even after the negative conversion of the viral RNA in the respiratory tract $[16,17,28]$. In a study by Santarpia et al (preprint), samples from the toilets in the infected patient room were positive in $81 \%$ of the rooms, with a mean concentration of 0.252 copies $/ \mu \mathrm{L}$, suggesting viral shedding during toileting [15]. The endoscopic examination in these patients with positive stool RNA showed normal mucosa with no significant damage to mucous epithelium with hematoxylin and eosin staining. However, numerous plasma cells and lymphocytes with interstitial edema were found in the lamina propria of the stomach, duodenum, and rectum. Most importantly, patients who had positive SARS-CoV-2 in the stool also tested positive for ACE2 and SARS-CoV-2 viral nucleocapsid protein staining in the glandular cells of the GI epithelium [17]. These findings, along with the unremarkable endoscopic findings in infected patients, are reminiscent of SARS-CoV-1 tropism to the intestinal epithelium [29].

\section{Effect of COVID-19 on immune system}

\section{Innate immunity}

Innate immunity appears to play a vital role in combatting against SARS-CoV-2 infection, but only limited data are available so far. In a study by Chen et al, among 99 patients with COVID-19 pneumonia, 38\% had a high neutrophil count, $35 \%$ had low lymphocytes, and $84 \%$ had elevated C-reactive protein [30]. In a prospective study by Huang et al, among 41 hospitalized COVID-19 patients, patients admitted to the intensive care unit (ICU) were found to have higher neutrophil and lower lymphocyte levels compared with non-ICU patients [31]. The patients in the ICU group were also found to have higher plasma levels of many innate cytokines, including IP-10, MCP-1, MIP-1A, and tumor necrosis factor (TNF)- $\alpha$. These findings suggest that a "cytokine storm" mediates disease severity in patients who have severe COVID-19, similarly to those with SARS-CoV-1 or MERS-CoV infection [32,33]. Previous studies based on SARS-CoV-1 showed that the 
"cytokine storm" was strongly associated with viral sepsis, inflammation-induced lung injury, and acute respiratory distress syndrome (ARDS) [32,34]. TNF- $\alpha$ plays a vital role across key points of the cytokine cascade of the "cytokine storm" syndrome [35]. Anti-TNF therapy has been shown to significantly reduce levels of cytokines and inflammatory markers in animal studies, with a significant reduction in mortality [36-38]. However, in previous clinical trials, the use of TNF- $\alpha$ antibodies did not show any mortality benefit in patients with severe sepsis $[39,40]$. Currently, there is an ongoing trial to study the efficacy of anti-interleukin (IL) drugs (anakinra, tocilizumab, siltuximab) in halting the cytokine storm and thereby preventing the progression from cytokine release syndrome to ARDS and multi-organ system failure [41].

Innate immunity against viral infection is dependent on the interferon (IFN) type I responses and its downstream cascade, which restricts the viral replication and induces an adaptive immune response [42]. To mount an antiviral response, invasion of the virus should be first recognized by the innate immune cells via pathogen-associated molecular patterns (PAMPs) [42]. For coronaviruses, viral RNA or the intermediates during viral replication, such as dsRNA, function as PAMPs. They are recognized by pattern recognition receptors such as TLR3/TLR7 and the cytosolic RNA sensor, RIG-I/MDA5 [42,43]. This recognition event activates the downstream signaling cascade, resulting in the expression of type I IFN and other proinflammatory cytokines, the first line of defense against the virus [44]. SARS-CoV-1 and MERS-CoV were known to utilize dampening strategies to suppress the type 1 INF response, closely associated with disease severity [45]. Given the close similarity of SARS-CoV-2 to SARS-CoV-1, it has been speculated that SARS-CoV-2 could be employing similar strategies to evade innate immunity and also may have additional novel mechanisms [42].

\section{Adaptive Immunity}

\section{Humoral immunity}

SARS-CoV-2 infection has a significant impact on both humoral and cellular immunity. Humoral immunity is responsible for antibody production with protection against future infection. In a study by Zhou et al, serology from 7 patients with severe COVID-19 pneumonia showed a peak in IgM at day nine after disease onset and a switch to IgG by week 2 [46]. A similar pattern of antibody production was also seen against the SARS-CoV-1 infection. The IgM antibodies are the first-line antibodies during the acute or early convalescent period, while IgG antibodies are antigen-specific antibodies that peak at week 12 and are supposed to be protective against future infection [47].

\section{Cellular immunity}

Helper T cells play an essential role in the overall adaptive response, with cytotoxic $\mathrm{T}$ cells involved in the killing of the infected cells. The cytokine response generated by the antigenpresenting cells orchestrates the initial T cell response. Patients with COVID-19 were found to have a significant reduction in their peripheral $\mathrm{CD}^{+}$and $\mathrm{CD}^{+} \mathrm{T}$ cells, but these cells had a hyperactive status, as evidenced by high proportions of HLADR and CD38 double-positive fractions [48].

\section{Risk factors for SARS-CoV-2 infection in IBD}

So far, there is no evidence to suggest that SARS-CoV-2 infection occurs more frequently in IBD patients compared with non-IBD individuals $[13,49]$. Nor is there any known difference between $\mathrm{CD}$ and $\mathrm{UC}$ in terms of infection risk. It is still uncertain whether the presence of active bowel inflammation would increase the risk of SARS-CoV-2 infection. Similar to the general population, IBD patients are at increased risk of infection if they travel to high-risk regions and if they have had close contact with a COVID-19 patient. With regard to IBD-specific risk factors, it is speculated that patients on immunosuppressive agents, those with active IBD symptoms, malnutrition, and frequent visits to clinics or hospitals are at greater risk of acquiring SARS-CoV-2 infection [50]. In an Italian study of 79 IBD patients, the risk factors associated with COVID-19-related mortality included age $>65$ years (OR 19.6, 95\%CI 2.95-130.6), Charlson comorbidity index $>1$ (OR 16.6, 95\%CI 1.80-153.9), and active IBD (OR 8.5, 95\%CI 1.2656.56) [51]. Table 1 outlines the risk factors for COVID-19 infection and poor outcomes [2-4,7,13,51]. Recent evidence suggests that the use of proton pump inhibitors is associated with an increased risk of SARS-CoV-2 infection and also potentially increases the risk of poor outcomes, such as death and mechanical ventilation $[52,53]$.

\section{Data from the Surveillance Epidemiology of Coronavirus Under Research Exclusion (SECURE-IBD) registry}

The International Organization for the Study of Inflammatory Bowel Diseases (IOIBD) maintains a registry for reporting COVID-19 in IBD patients called SECURE-IBD registry. Using the SECURE-IBD database, IBD physicians can report confirmed cases of COVID-19 in their IBD patients, regardless of severity, including the asymptomatic patients detected through public health screening [54]. As of June $14^{\text {th }}$, 2020 , there were 1439 IBD patients reported to be infected with COVID-19 (Fig. 1) in the SECURE-IBD database globally [54]. Table 2 summarizes the latest data from the SECURE-IBD database as of June $14^{\text {th }}, 2020$. Brenner et al published the data from the SECURE-IBD registry with 525 reported cases; currently, 1439 cases have been reported. Based on that study, among the 525 cases reported from 33 countries, 31\% were hospitalized, $7 \%$ had severe COVID-19, and $3 \%$ of the patients died [55]. 
Table 1 Risk factors for COVID-19 in inflammatory bowel disease (IBD)

\begin{tabular}{|c|c|c|}
\hline Speculative IBD-related risk factors & Risk factors for infection & Risk factors for severe disease \\
\hline $\begin{array}{l}\text { - On immunosuppressive agents, especially } \\
\text { new induction combo therapy within the } \\
\text { previous } 6 \text { weeks [84] } \\
\text { - Short gut syndrome on total parenteral } \\
\text { nutrition [84] }\end{array}$ & $\begin{array}{l}\text { - Travel to high-risk regions such as level } 2 \\
\text { or level } 3 \text { countries [101] } \\
\text { - Close contact with a COVID-19 patient } \\
\text { [102] } \\
\text { - Healthcare workers [102] }\end{array}$ & $\begin{array}{l}\text { - Age }>65 \text { years }[2,3] \\
\text { - Cardiovascular disease }[2] \\
\text { - Chronic pulmonary disease }[2] \\
\text { - Males [2] } \\
\text { - Hypertension }[2] \\
\text { - Diabetes mellitus [2] } \\
\text { - Obesity [2] } \\
\text { - Cancer [103] } \\
\text { - On corticosteroids, especially prednisone } \geq 20 \\
\text { mg per day }[84,51] \\
\text { - Active IBD }[84,51]\end{array}$ \\
\hline
\end{tabular}

Table 2 Data from the SECURE-IBD registry* [54]

\begin{tabular}{|c|c|}
\hline Variables & Number $(\%)$ \\
\hline Total number of cases reported & 1439 \\
\hline Hospitalization & $427(30 \%)$ \\
\hline Severe COVID-19 status (ICU/ventilator/death) & $112(8 \%)$ \\
\hline ICU & $82(6 \%)$ \\
\hline Mechanical ventilation & $66(5 \%)$ \\
\hline Death & $49(3 \%)$ \\
\hline Number of cases in the United States & $496(34.5 \%)$ \\
\hline Age $>60$ years & $292(20.3 \%)$ \\
\hline Male & $739(51.4 \%)$ \\
\hline $\begin{array}{l}\text { Type of IBD } \\
\text { Crohn's disease } \\
\text { Ulcerative colitis/unspecified }\end{array}$ & $\begin{array}{l}795(55.2 \%) \\
637(44.3 \%)\end{array}$ \\
\hline $\begin{array}{l}\text { IBD disease activity } \\
\text { Remission } \\
\text { Mild } \\
\text { Moderate / severe } \\
\text { Unknown }\end{array}$ & $\begin{array}{c}821(57.1 \%) \\
258(17.9 \%) \\
302(20.9 \%) \\
58(4.1 \%)\end{array}$ \\
\hline Current smoker & $68(4.7 \%)$ \\
\hline $\begin{array}{l}\text { Number of comorbidities } \\
0 \\
1 \\
2 \\
3+\end{array}$ & $\begin{array}{c}904(62.8 \%) \\
335(23.3 \%) \\
113(7.9 \%) \\
87(6 \%)\end{array}$ \\
\hline $\begin{array}{l}\text { IBD medications (not mutually exclusive) } \\
\text { Aminosalicylates } \\
\text { Budesonide } \\
\text { Systemic steroids } \\
\text { Thiopurines (AZA/6-MP) } \\
\text { Mtx } \\
\text { Anti-TNF agents } \\
\text { Combination therapy (Anti-TNF + 6-MP/AZA/Mtx) } \\
\text { Anti-integrin } \\
\text { Interleukin } 12 / 23 \text { inhibitor } \\
\text { Janus kinase inhibitor } \\
\text { Other medications }\end{array}$ & $\begin{array}{c}440(30.6 \%) \\
37(2.6 \%) \\
114(7.9 \%) \\
141(9.8 \%) \\
11(0.8 \%) \\
417(28.9 \%) \\
137(9.5 \%) \\
141(9.8 \%) \\
132(9.2 \%) \\
19(1.3 \%) \\
55(3.8 \%)\end{array}$ \\
\hline
\end{tabular}

\section{GI manifestations of COVID-19}

The most common symptoms in COVID-19 are fever and respiratory symptoms, followed by GI symptoms such as diarrhea, vomiting, anorexia, dysgeusia, and abdominal pain [4,56-59]. Based on the SECURE-IBD registry-based study, about $30 \%$ of the patients reported an increase in baseline IBD symptoms [55]. Among the IBD patients, diarrhea was the most common symptom (25.5\%), followed by abdominal pain (8.4\%), nausea (5.7\%), and vomiting (3.2\%) [55]. In contrast, among non-IBD patients, studies have reported diarrhea in $2-10 \%$, nausea or vomiting in $1-10 \%$ and abdominal pain in $2.2-5.8 \%$ [60-62]. The diagnosis of IBD flare-up is challenging in the context of COVID-19, as the typical presenting features of IBD, such as diarrhea, abdominal pain and fever, along with elevated inflammatory markers, may also be secondary to COVID-19 [63,64]. However, rectal bleeding is not common in COVID-19 [63]. Laboratory tests such as C-reactive protein and ferritin are elevated in both conditions, although occasionally ferritin can be low in UC. Patients with COVID-19 have lymphopenia, whereas in IBD patients, lymphocyte levels are usually normal or elevated. The red blood cell distribution width index has been found to be elevated in nearly half of patients with COVID-19 and has been found to be associated with an increased risk of in-hospital mortality (adjusted OR [aOR] 4.5, 95\%CI 1.4-14.3) and septic shock (aOR 4.6, 95\%CI 1.4-15.1) [65]. In all cases, standard stool tests, such as stool culture and stool Clostridium difficile (C. difficile) toxin, should also be performed. For patients with severe GI symptoms, abdominal computed tomography or endoscopic evaluation should be considered to assess the bowel inflammation to determine appropriate management.

\section{The potential effect of IBD medications on COVID-19}

\section{Non-immunosuppressive medications}

Based on recommendations from the IBD societies, nonimmunosuppressive medications such as 5-aminosalicylates ([5-ASA], mesalamine) and locally acting steroids 
(budesonide, steroid enema) should be continued even if the patient has COVID-19 [66,67]. Surprisingly, the study from the SECURE-IBD registry observed that patients on 5-ASA/sulfasalazine treatment had 3 times as great a risk (aOR 3.1, 95\%CI 1.3-7.7) of poor outcomes such as ICU admission, mechanical ventilation or death [55]. This finding persisted even after controlling for age, comorbidities, IBD disease characteristics, corticosteroid use, and other factors. Furthermore, in a direct comparison, patients treated with 5-ASA/sulfasalazine had worse outcomes than those treated with TNF inhibitors [55]. Further studies are needed to confirm whether this association is real and to explore the biological mechanisms that may contribute to these poor outcomes.

\section{Steroids}

Prednisone at doses of more than $20 \mathrm{mg}$ per day impairs the immune response [66-68]. Corticosteroids affect the immune system via multiple mechanisms, including inhibition of adhesion molecules, inducing apoptosis of activated lymphocyte, and decreasing the expression of inflammatory cytokines [69]. Based on a large international registry-based study, among IBD patients, those on systemic corticosteroids had 6.9 times (aOR 6.9, 95\%CI 2.3-20.5) greater odds of a poor outcome such as ICU care, mechanical ventilation or death [55]. Studies based on MERS and SARS-CoV-1 have reported delayed viral clearance in patients receiving highdose corticosteroids [70]. The use of short-term steroids for the treatment of ARDS and hyper-inflammation in COVID-19 is controversial. One study by Wu et al showed that in COVID-19 patients with ARDS, treatment with methylprednisolone decreased the risk of mortality by $62 \%$ (hazard ratio 0.38 , 95\%CI 0.20-0.72) [71].

\section{Immunomodulators}

Immunomodulators, such as azathioprine, 6-mercaptopurine (6-MP) and methotrexate, inhibit the body's immune response to viral infections. Azathioprine and 6-MP interfere with DNA and RNA synthesis, thereby inhibiting the proliferation of T- and B-lymphocytes [72]. Overall, the thiopurines can reduce the number of activated $\mathrm{T}$ cells and also affect T-cell function [70]. Methotrexate inhibits DNA synthesis, repair and cellular replication by interfering with folate metabolism [73]. Hence, actively proliferating cells are more susceptible to the effects of methotrexate. There are no data currently available on how the changes in the immune system by these immunomodulatory medications affect the course of IBD patients with COVID-19.

\section{Biologics}

Biologics are the key immunosuppressive medication group used in the management of IBD. These medications include infliximab, adalimumab, golimumab, certolizumab pegol, ustekinumab, and vedolizumab. Activated macrophages and T-cells secrete TNF, which plays an integral role in cellmediated immunity [74]. TNF- $\alpha$ plays a vital role in inducing bowel inflammation by induction of ILs, facilitating leukocyte migration, activation of neutrophils, and the induction of acute-phase reactants. Thus, TNF inhibitors are very effective against the heightened inflammatory response seen in IBD. However, this impacts the effectiveness of the host immune system response against infectious organisms, especially intracellular pathogens, such as mycobacteria, fungi and viral infections [75]. In a study by Brenner et al, no association was found between TNF inhibitor use and severe COVID-19 [55]. In a prospective study of 65 IBD patients from the University of Miami, the use of TNF inhibitors such as vedolizumab and ustekinumab was associated with lower expression of ACE2 in CD11b-enriched cells [76]. Elevated serum TNF- $\alpha$ levels have been observed in patients with COVID-19 infection, and were positively correlated with disease severity. Even though anti-TNF treatment was explored as a potential treatment for COVID-19, there are no sufficient data to date [77]. Tocilizumab, an IL-6 inhibitor, is currently under investigation for cytokine release syndrome triggered by COVID-19 [78].

\section{Janus kinase (JAK) inhibitors}

Tofacitinib is an FDA-approved JAKinhibitor for the treatment of moderate-to-severe UC in patients who are refractory to biologic agents. JAK inhibitors are smaller sized molecules, with a rapid onset of action, that cause immunosuppression by blocking multiple pathways of inflammation to control the inflammation of the intestines. In a New York-based study on COVID-19 patients receiving JAK inhibitors for underlying inflammatory disorders, there was no increase in the rate of hospitalizations [79]. However, it is important to consider the higher risk of blood clots in patients on tofacitinib treatment, since COVID-19 infection is strongly associated with hypercoagulability and venous thromboembolism in up to one third of patients with severe infection [80,81]. Interestingly, another JAK inhibitor, baricitinib, is being explored as a potential medication in the management of SARS-CoV-2 infection through its inhibitory action on Numb-associated kinase (NAK), involved in the endocytosis of SARS-CoV-2 [77]. Tofacitinib does not inhibit NAK.

\section{Cyclosporine}

Cyclosporine A is used in severe steroid-refractory UC patients. It is a polypeptide that suppresses $\mathrm{T}$ cell by inhibiting transcription of genes encoding IL-2 [82]. The primary molecular target of cyclosporine is a cytosolic binding protein called cyclophilin, also required by many viruses for replication, including the coronaviruses. It has been speculated that patients on cyclosporine treatment during the COVID-19 pandemic may experience a beneficial effect [83]. So far, no 
study has reported any benefits or risks of cyclosporine with COVID-19.

\section{Management of IBD patients during COVID-19 epidemic}

The care of the IBD patients has to be individualized based on whether the patient is infected with SARS-CoV-2, has symptomatic manifestations of COVID-19 and shows underlying activity of the IBD. We are still in the phase where studies are being actively published; this will soon help us determine the outcomes in IBD patients, and will also give a better objective measure of which recommendations can be followed and what needs to change. However, as of now, we are still largely dependent on anecdotal evidence, expert opinion and guidance from the societies to manage IBD patients during this current pandemic (Fig. 3). The societies that have issued guidance include the American Gastroenterological Association (AGA), the British Society of Gastroenterology (BSG), Crohn's and Colitis Canada, the European Crohn's and Colitis Organization, and the IOIBD [67,84-86].

\section{IBD patients without SARS-CoV-2 infection}

The current evidence shows that IBD patients are not at a higher risk of developing SARS-CoV-2 infection compared with non-IBD patients $[13,66]$. Hence, all the societies have recommended that patients continue their IBD medications to sustain remission, because the risk of disease flare-up outweighs the chance of contracting SARS-CoV-2 infection. Furthermore, a relapse in IBD may require steroid therapy or hospitalization, known risk factors for SARS-CoV-2 infection [67]. The emphasis should be on enforcing preventive strategies, such as social distancing and hand hygiene, and to avoid contact with infected individuals [66]. The BSG has categorized IBD patients into 3 categories based on their medications (Table 3) [84]. The patients in the highest-risk group have been recommended to practice "shielding", the most stringent version of isolation. The patients in the moderate risk group should follow "stringent social distancing", and those in the lowest risk group should follow "social distancing" practices. In a study published from Wuhan, proactive measures were taken by the medical team by sending educational materials and instructions on COVID-19 prevention to all registered IBD patients $(\mathrm{N}=318)$. By enforcing these preventive measures, they were able to achieve a "zero infection" rate among their IBD patients [87]. Another concern was the risk of SARS-CoV-2 infection among IBD patients who are on infusion therapies such as infliximab, vedolizumab and ustekinumab, for which the patients need to go to the infusion centers. However, the consensus statement from the IOIBD recommended continuing infusions in an infusion center, as long as the infusion centers have protocols to screen for COVID-19 exposure and symptoms, including fever checks at the door [66]. It is also recommended that the infusion centers provide a minimum of 2-meter spacing between patients' chairs, provide the patients with gloves, ensure mask and glove

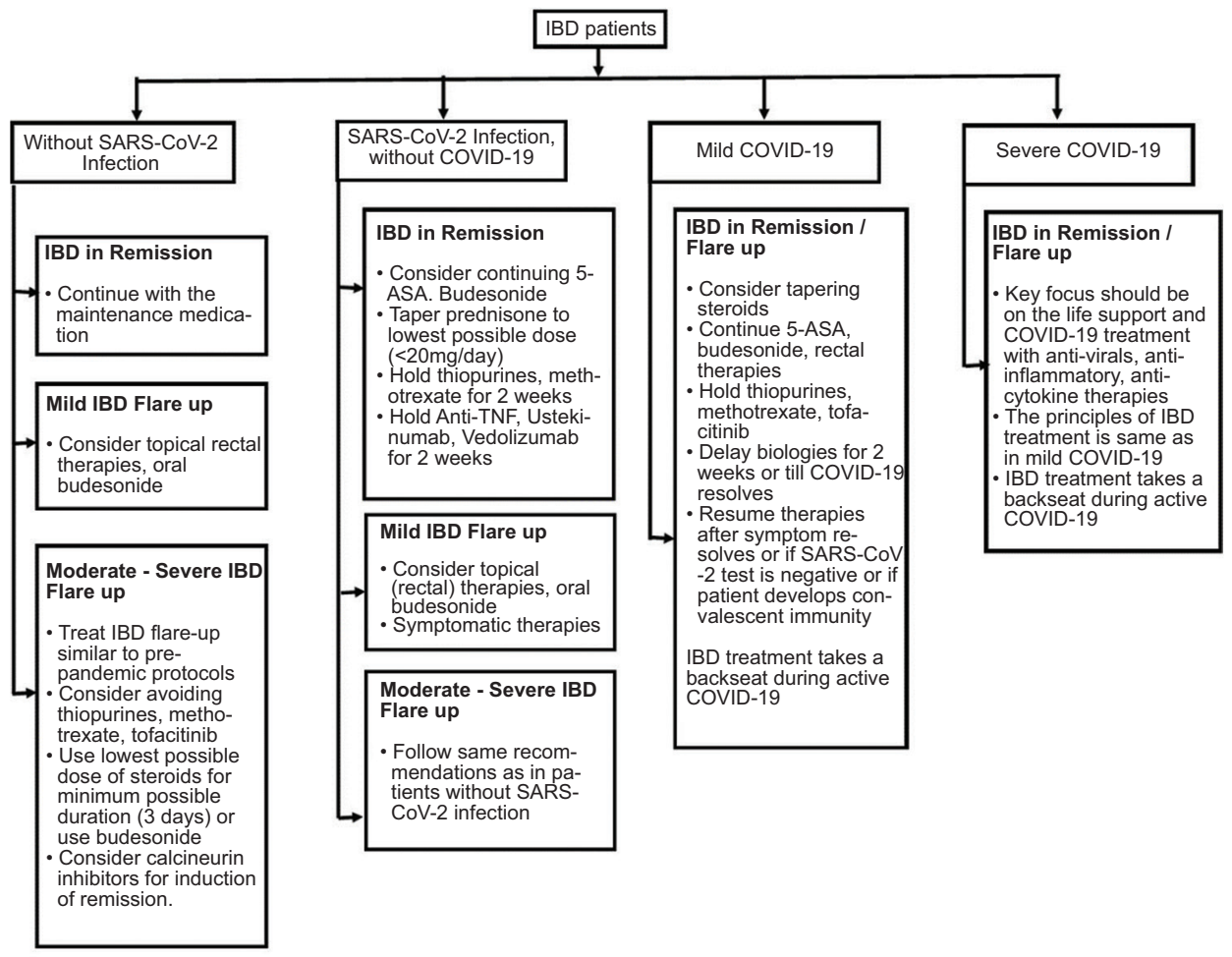

Figure 3 Inflammatory bowel disease (IBD) management during COVID-19 pandemic 
use by the providers, and carry out adequate deep cleaning after the patient's departure [67]. Other strategies cited by other societies include moving infusion centers to "clean sites" in order to keep IBD patients away from centers that admit or review patients with COVID-19.

\section{IBD patients who have SARS-CoV-2 infection without manifestations of COVID-19}

As the testing capability of SARS-CoV-2 becomes widespread, we will encounter patients who are asymptomatic but have had a positive test for SARS-CoV-2 infection. These patients should be closely monitored for the development of COVID-19 for at least 2 weeks. It has been recommended that 5-ASA medications be continued in these patients, but it is unclear why patients on 5-ASA had poor outcomes in the SECURE-IBD study (Table 4) [55,88]. For patients on prednisone, it should be tapered off if feasible, but if this is not possible, then at least the dose should be reduced below 20 $\mathrm{mg} / \mathrm{d}$ or transitioned to budesonide [67]. Immunosuppressive medications, such as azathioprine, 6-mercaptopurine and methotrexate, should be stopped temporarily [88]. For monoclonal antibody therapies, such as anti-TNF agents, ustekinumab and vedolizumab, the dosing should be delayed for 2 weeks and can be resumed after 2 weeks if the patient has not developed symptoms of COVID-19 [67]. The current approach to monitoring these patients could change with the development of point-of-care tests and serologic antibodies [89].

\section{IBD patients with manifestations of COVID-19}

There are many unique challenges and dilemmas that need to be taken into account when managing an IBD patient with COVID-19. The management strategy will depend on multiple factors, such as the patient's age, the severity of the COVID-19 infection, the clinical status of the IBD, and the presence of other comorbid conditions. The management of these patients should be individualized, with a 2-pronged approach to manage both COVID-19 and IBD. Adjustment

Table 3 Stratifications of IBD patients according to the British Society of Gastroenterology [84]

\begin{tabular}{|c|c|c|}
\hline Highest risk & Moderate risk & Lowest risk \\
\hline $\begin{array}{l}\text { - Patients with comorbid conditions (pulmonary, } \\
\text { cardiac, diabetes mellitus, hypertension) and } \\
\text { are on "moderate risk medications" for IBD and } \\
\text { / or have moderate-to-severe active IBD } \\
\text { - Patients above } 70 \text { years of age and are on } \\
\text { "moderate risk medications" for IBD and / or } \\
\text { have moderate-to-severe active IBD } \\
\text { - On prednisolone } \geq 20 \mathrm{mg} \text { /day [66] } \\
\text { - New induction combo therapy (biologic with } \\
\text { immunomodulator) within the previous } 6 \\
\text { weeks } \\
\text { - Total parenteral nutrition } \\
\text { - Short gut syndrome on nutritional support }\end{array}$ & $\begin{array}{l}\text { - Anti-TNF monotherapy (infliximab, adalimumab, } \\
\text { certolizumab, golimumab) } \\
\text { - Ustekinumab } \\
\text { - Vedolizumab } \\
\text { - Thiopurines (azathioprine, 6-mercaptopurine) } \\
\text { - Methotrexate } \\
\text { - Combination therapy (Biologic with } \\
\text { Immunomodulators) } \\
\text { - JAK inhibition (tofacitinib) } \\
\text { - Calcineurin inhibitors (tacrolimus or cyclosporine) } \\
\text { - Prednisone <20 mg /day } \\
\text { - Mycophenolate mofetil } \\
\text { - Thalidomide } \\
\text { - Moderate-to-severe disease who are not on } \\
\text { "moderate risk medications" for IBD }\end{array}$ & $\begin{array}{l}\text { - 5- aminosalicylates } \\
\text { - Rectal therapies } \\
\text { - Budesonide or beclomethasone } \\
\text { - Bile acid sequestrants } \\
\text { (cholestyramine, colesevelam) } \\
\text { - Anti-diarrheal (e.g., loperamide) } \\
\text { - Antibiotics for bacterial overgrowth } \\
\text { or perianal disease }\end{array}$ \\
\hline
\end{tabular}

IBD, inflammatory bowel disease; TNF, tumor necrosis factor; JAK, Janus kinase;

Table 4 Recommendations on inflammatory bowel disease medications based on the International Organization for the Study of Inflammatory Bowel Diseases consensus [66]

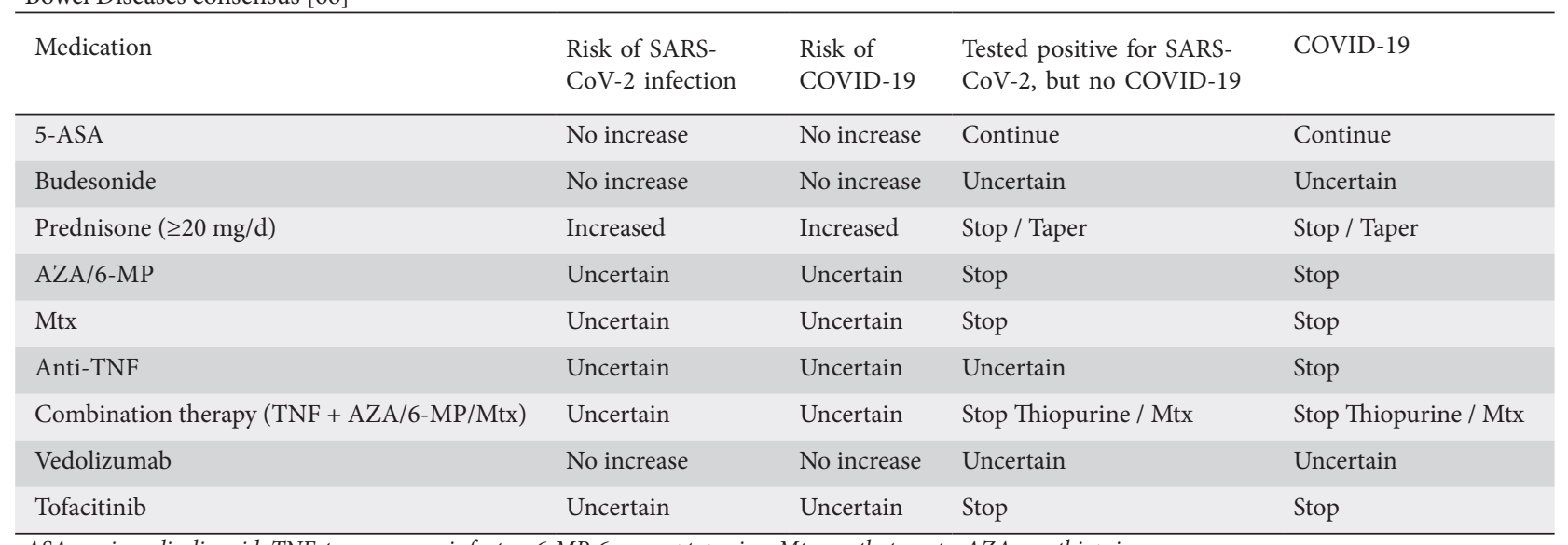

ASA, aminosalicylic acid; TNF, tumor necrosis factor; 6-MP, 6-mercaptopurine; Mtx, methotrexate; AZA, azathioprine 
to IBD medications is mainly focused on reducing the level of immunosuppression during active COVID-19, with the goal of preventing complications. Table 4 outlines the critical medication management recommendations from the IOIBD expert panel consensus [66].

\section{IBD in remission with mild COVID-19}

In terms of IBD medications, it is safe to continue nonimmunosuppressive medications, such as topical, rectal therapy and antibiotics [67]. Oral budesonide or beclomethasone may be safely continued to maintain remission. However, if the patient is on systemic corticosteroids, such as prednisone, it should be tapered quickly whenever possible, because of concerns over the immunosuppressive effect of steroids, which could increase the risk of severe infection [55,90,91]. In addition, observational studies from past epidemics (SARSCoV-1, MERS-CoV) showed delayed clearance of viral RNA in patients on corticosteroid therapy [92,93]. The COVID-19 should be treated with supportive care, and self-quarantine until the symptoms resolve. Patients should be encouraged to contact their healthcare provider by phone for guidance about clinical management. Telemedicine should be utilized in such patients to minimize the spread of infection.

\section{Active IBD symptoms with mild COVID-19}

In patients with active GI symptoms suggestive of IBD flare-up, the workup should be targeted to find the cause for the relapse. The stool should be tested for C. difficile and other enteric pathogens. The presence of active inflammation can be assessed by testing C-reactive protein, fecal calprotectin or cross-sectional imaging. According to Joint GI society recommendations, endoscopic procedures should be reserved only for urgent and emergent indications during the COVID-19 pandemic [66]. For mildly active disease, nonimmunosuppressive medications can be used. For moderate to severe disease, the risks and benefits of escalating IBD therapy must be carefully weighed against the severity of the COVID-19 [67]. If the patient has only mild COVID-19, then the IBD flare-up should be treated similarly to the treatment that would have been considered before the pandemic. However, it is still essential to avoid or limit the use of corticosteroids, given their association with poor outcomes. In patients hospitalized for severe IBD who have mild COVID-19, intravenous steroids should be limited to 3 days, and consideration should be given to the use of either infliximab or a calcineurin inhibitor for induction of remission [67].

\section{Severe COVID-19}

In patients hospitalized for severe COVID-19, the priority should be given to the treatment of the COVID-19. In patients presenting with severe COVID-19 along with severe IBD flare-up, the management becomes challenging. Severe IBD, such as acute severe UC (ASUC), is typically managed with high-dose parenteral corticosteroids [94]. If these patients fail to respond adequately, then they are treated with rescue therapy, such as infliximab, along with steroids [94]. According to the RAND appropriateness panel on the management of ASUC in patients with COVID-19 pneumonia, there was uncertainty among the panel regarding the first-line therapy [95]. However, among all the suggested treatments, intravenous steroids were given the highest score by the panel. At that time, the results from the RECOVERY trial were not available [96]. In the RECOVERY trial, the dexamethasone group had a lower mortality rate compared with the usual care group in patients receiving mechanical ventilation $(29.3 \%$ vs. $41.4 \%$; rate ratio $0.64,95 \% \mathrm{CI}$ $0.51-0.81)$ and among those on supplemental oxygen $(23.3 \%$ vs. $26.2 \%$; rate ratio $0.82,95 \%$ CI $0.72-0.94)$ [96]. The dose of dexamethasone used in the RECOVERY trial was $6 \mathrm{mg}$ q.d. for 10 days. The usual intravenous steroids used in ASUC include methylprednisolone (20 mg t.i.d.) or hydrocortisone (100 mg t.i.d.) [97]. Dexamethasone at a $6 \mathrm{mg}$ dose is equivalent to $32 \mathrm{mg}$ of methylprednisolone or $160 \mathrm{mg}$ of hydrocortisone [98]. In addition, dexamethasone is long-acting (26-72 h), whereas methylprednisolone and hydrocortisone last for 8-12 h [98]. Finally, if the patient fails to improve despite rescue therapy or develops complications, then surgical intervention should be undertaken. It was deemed inappropriate to delay surgery, even in patients with COVID-19 pneumonia.

\section{Endoscopy in IBD patients}

Multiple societies have recommended suspending all routine non-urgent endoscopic procedures during the COVID-19 pandemic [58]. Hence, only urgent and emergent endoscopic procedures are being done currently, which could potentially change a patient's management. Some of the clinical scenarios that would need an endoscopic procedure are the new diagnosis of severe IBD, which needs tissue diagnosis for confirmation of diagnosis, to rule out cytomegalovirus infection in cases where a serum polymerase chain reaction was inconclusive, and when cancer is suspected [99]. The AGA recommends the uses of N95 (or N99 or PAPR) masks and double gloving as a part of PPE for the healthcare worker performing the endoscopic examination, regardless of the COVID-19 status $[58,100]$.

\section{Concluding remarks}

COVID-19 is the latest threat to global health; it has developed into a public health emergency and is a reminder of the ongoing challenge of emerging infectious pathogens. The most important question is how to modify the medication regimen in IBD patients with SARS-CoV-2 infection, without increasing the risk of complications from either the COVID-19 or the IBD itself. The data published so far have 
been reassuring and do not appear to indicate that IBD patients are at greater risk or severe COVID-19 compared with the general population. Most of the guidelines have reinforced the importance of avoiding systemic corticosteroids for managing IBD and maintaining remission by recommending compliance with maintenance medications. If an IBD patient does develop COVID-19, it is important for them to immediately contact the IBD physicians to determine whether to continue the immunosuppressive medications or withhold them until infection resolution. It is essential for the IBD community, including the patient, physicians and advanced practice providers, to recommend and implement stringent prevention strategies. As the SARS-CoV-2 virus is rapidly evolving, our experience and understanding of its impact on the IBD population may potentially change in the near future.

\section{References}

1. Johns Hopkins University COVID-19 Dashboard. [Accessed on July 21, 2020]. Available from: https://coronavirus.jhu.edu/map. html.

2. Garg S. Hospitalization rates and characteristics of patients hospitalized with laboratory-confirmed coronavirus disease 2019-COVID-NET, 14 States, March 1-30, 2020. MMWR Morbidity and Mortality Weekly Report 2020;69

3. Grasselli G, Zangrillo A, Zanella A, et al; COVID-19 Lombardy ICU Network. Baseline characteristics and outcomes of 1591 patients infected with SARS-CoV-2 admitted to ICUs of the Lombardy region, Italy. JAMA 2020;323:1574-1581.

4. Guan WJ, Ni ZY, Hu Y, et al; China Medical Treatment Expert Group for Covid-19. Clinical characteristics of coronavirus disease 2019 in China. N Engl J Med 2020;382:1708-1720.

5. Kopel J, Perisetti A, Gajendran M, Boregowda U, Goyal H. Clinical insights into the gastrointestinal manifestations of COVID-19. Dig Dis Sci 2020;65:1932-1939.

6. Onder G, Rezza G, Brusaferro S. Case-fatality rate and characteristics of patients dying in relation to COVID-19 in Italy. JAMA 2020;323:1775-1776.

7. Ruan Q, Yang K, Wang W, Jiang L, Song J. Clinical predictors of mortality due to COVID-19 based on an analysis of data of 150 patients from Wuhan, China. Intensive Care Med 2020;46:846-848.

8. Alatab S, Sepanlou SG, Ikuta K, et al; GBD 2017 Inflammatory Bowel Disease Collaborators. The global, regional, and national burden of inflammatory bowel disease in 195 countries and territories, 1990-2017: a systematic analysis for the Global Burden of Disease Study 2017. Lancet Gastroenterol Hepatol 2020;5:17-30.

9. Loftus EV Jr, Sandborn WJ. Epidemiology of inflammatory bowel disease. Gastroenterol Clin North Am 2002;31:1-20.

10. Langan RC, Gotsch PB, Krafczyk MA, Skillinge DD. Ulcerative colitis: diagnosis and treatment. Am Fam Physician 2007;76:1323-1330.

11. Manninen P, Karvonen AL, Huhtala H, Rasmussen M, Collin P. The epidemiology of inflammatory bowel diseases in Finland. Scand J Gastroenterol 2010;45:1063-1067.

12. Longobardi T, Bernstein CN. Health care resource utilization in inflammatory bowel disease. Clin Gastroenterol Hepatol 2006;4:731-743.

13. Gubatan J, Levitte S, Balabanis T, Patel A, Sharma A, Habtezion A. SARS-CoV-2 testing, prevalence, and predictors of COVID-19 in patients with inflammatory bowel disease in Northern California. Gastroenterology 2020;159:1141-1144.

14. Gu J, Han B, Wang J. COVID-19: Gastrointestinal manifestations and potential fecal-oral transmission. Gastroenterology 2020;158:1518-1519.

15. Santarpia JL, Rivera DN, Herrera VL, et al. Aerosol and surface contamination of SARS-CoV-2 observed in quarantine and isolation care. Sci Rep 2020;10:12732.

16. Wu Y, Guo C, Tang L, et al. Prolonged presence of SARS-CoV-2 viral RNA in faecal samples. Lancet Gastroenterol Hepatol 2020;5:434-435.

17. Xiao F, Tang M, Zheng X, et al. Evidence for gastrointestinal infection of SARS-CoV-2. Gastroenterology 2020;158:1831-1833.e3.

18. Jess T, Winther KV, Munkholm P, Langholz E, Binder V. Mortality and causes of death in Crohn's disease: follow-up of a populationbased cohort in Copenhagen County, Denmark. Gastroenterology 2002;122:1808-1814.

19. Irving PM, Gibson PR. Infections and IBD. Nat Clin Pract Gastroenterol Hepatol 2008;5:18-27.

20. Tinsley A, Navabi S, Williams ED, et al. Increased risk of influenza and influenza-related complications among 140,480 patients with inflammatory bowel disease. Inflamm Bowel Dis 2019;25:369-376.

21. Fan YY, Huang ZT, Li L, et al. Characterization of SARS-CoVspecific memory T cells from recovered individuals 4 years after infection. Arch Virol 2009;154:1093-1099.

22. Lai MM. SARS virus: the beginning of the unraveling of a new coronavirus. J Biomed Sci 2003;10:664-675.

23. Harmer D, Gilbert M, Borman R, Clark KL. Quantitative mRNA expression profiling of ACE 2, a novel homologue of angiotensin converting enzyme. FEBS Lett 2002;532:107-110.

24. van D N, Bushmaker T, Morris DH, et al. Aerosol and surface stability of SARS-CoV-2 as compared with SARS-CoV-1. New Engl J Med 2020;382:1564-1567.

25. Weiss SR, Navas-Martin S. Coronavirus pathogenesis and the emerging pathogen severe acute respiratory syndrome coronavirus. Microbiol Mol Biol Rev 2005;69:635-664.

26. Millet JK, Whittaker GR. Host cell proteases: Critical determinants of coronavirus tropism and pathogenesis. Virus Res 2015;202:120-134.

27. Wang J, Zhao S, Liu M, et al. ACE2 expression by colonic epithelial cells is associated with viral infection, immunity and energy metabolism. medRxiv 2020. doi: 10.1101/2020.02.05.20020545

28. Zhao F, Yang Y, Wang Z, Li L, Liu L, Liu Y. The time sequences of oral and fecal viral shedding of coronavirus disease 2019 (COVID-19) patients. Gastroenterology 2020;159:1158-1160.e2.

29. Leung WK, To KF, Chan PK, et al. Enteric involvement of severe acute respiratory syndrome-associated coronavirus infection. Gastroenterology 2003;125:1011-1017.

30. Chen N, Zhou M, Dong X, et al. Epidemiological and clinical characteristics of 99 cases of 2019 novel coronavirus pneumonia in Wuhan, China: a descriptive study. Lancet 2020;395:507-513.

31. Huang C, Wang Y, Li X, et al. Clinical features of patients infected with 2019 novel coronavirus in Wuhan, China. Lancet 2020;395:497-506.

32. Wong CK, Lam CW, Wu AK, et al. Plasma inflammatory cytokines and chemokines in severe acute respiratory syndrome. Clin Exp Immunol 2004;136:95-103.

33. Mahallawi WH, Khabour OF, Zhang Q, Makhdoum HM, Suliman BA. MERS-CoV infection in humans is associated with a pro-inflammatory Th1 and Th17 cytokine profile. Cytokine 2018;104:8-13.

34. Nicholls JM, Poon LL, Lee KC, et al. Lung pathology of fatal severe acute respiratory syndrome. Lancet 2003;361:1773-1778.

35. Macaluso FS, Orlando A. Could patients with inflammatory bowel disease treated with immunomodulators or biologics be at lower risk for severe forms of covid-19? Gastroenterology 2020. doi: 10.1053/j.gastro.2020.05.026.

36. Grewal HP, el D AM, Gaber L, Kotb M, Gaber AO. Amelioration of the physiologic and biochemical changes of acute pancreatitis using 
an anti-TNF-Î̀ polyclonal antibody. Am J Surg 1994;167:214-219.

37. Hughes CB, Grewal HP, Gaber LW, et al. Anti-TNFalpha therapy improves survival and ameliorates the pathophysiologic sequelae in acute pancreatitis in the rat. Am J Surg 1996;171:274-280.

38. Norman JG, Fink GW, Messina J, Carter G, Franz MG. Timing of tumor necrosis factor antagonism is critical in determining outcome in murine lethal acute pancreatitis. Surgery 1996;120:515-521.

39. Abraham E, Wunderink R, Silverman H, et al. Efficacy and safety of monoclonal antibody to human tumor necrosis factor alpha in patients with sepsis syndrome. A randomized, controlled, doubleblind, multicenter clinical trial. TNF-alpha MAb Sepsis Study Group. JAMA 1995;273:934-941.

40. Bernard GR, Francois B, Mira JP, et al. Evaluating the efficacy and safety of two doses of the polyclonal anti-tumor necrosis factor- $\alpha$ fragment antibody AZD9773 in adult patients with severe sepsis and/or septic shock: randomized, double-blind, placebo-controlled phase IIb study ${ }^{\star}$. Crit Care Med 2014;42:504-511.

41. Treatment of COVID-19 patients with anti-interleukin drugs (COV-AID) [Accessed on May 21, 2020]. Available from: https:// clinicaltrials.gov/ct2/show/NCT04330638

42. Prompetchara E, Ketloy C, Palaga T. Immune responses in COVID-19 and potential vaccines: Lessons learned from SARS and MERS epidemic. Asian Pac J Allergy Immunol 2020;38:1-9.

43. LiX, Geng M, Peng Y, Meng L, Lu S. Molecular immune pathogenesis and diagnosis of COVID-19. J Pharm Anal 2020;10:102-108.

44. de Wit E, van Doremalen N, Falzarano D, Munster VJ. SARS and MERS: recent insights into emerging coronaviruses. Nat Rev Microbiol 2016;14:523-534.

45. Channappanavar R, Perlman S. Pathogenic human coronavirus infections: causes and consequences of cytokine storm and immunopathology. Seminars in immunopathology: Springer 2017;39: pp.529-539.

46. Zhou P, Yang XL, Wang XG, et al. A pneumonia outbreak associated with a new coronavirus of probable bat origin. Nature 2020;579:270-273.

47. Li G, Chen X, Xu A. Profile of specific antibodies to the SARSassociated coronavirus. N Engl J Med 2003;349:508-509.

48. Xu Z, Shi L, Wang Y, et al. Pathological findings of COVID-19 associated with acute respiratory distress syndrome. Lancet Respir Med 2020;8:420-422.

49. Monteleone G, Ardizzone S. Are patients with inflammatory bowel disease at increased risk for Covid-19 infection? J Crohns Colitis 2020;14:1334-1336.

50. Mao R, Liang J, Shen J, et al; Chinese IBD Quality Care Evaluation Center Committee. Implications of COVID-19 for patients with pre-existing digestive diseases. Lancet Gastroenterol Hepatol 2020;5:425-427.

51. Bezzio C, Saibeni S, Variola A, et al; Italian Group for the Study of Inflammatory Bowel Disease (IG-IBD). Outcomes of COVID-19 in 79 patients with IBD in Italy: an IG-IBD study. Gut 2020;69:1213-1217.

52. Almario CV, Chey WD, Spiegel BMR. Increased risk of COVID-19 among users of proton pump inhibitors (preprint). Am $J$ Gastroenterol 2020. Available from: https://journals.lww.com/ajg/ Documents/AJG-20-1811_R1(PUBLISH AS WEBPART).pdf.

53. Ramachandran P, Perisetti A, Gajendran M, Jean-Louise F, Dwivedi AK, Goyal H. Prehospitalization proton pump inhibitor (PPI) use and clinical outcomes in COVID-19. medRxiv July 2020. doi: 10.1101/2020.07.12.20151084

54. Brenner EJ, Ungaro RC, Colombel JF, Kappelman MD. SECUREIBD Database Public Data Update. Available from: https:// covidibd.org/current-data/. Accessed on 06/14/20.

55. Brenner EJ, Ungaro RC, Gearry RB, et al. Corticosteroids, but not TNF antagonists, are associated with adverse COVID-19 outcomes in patients with inflammatory bowel diseases: results from an international registry. Gastroenterology 2020;159:481-491.
56. Aloysius MM, Thatti A, Gupta A, Sharma N, Bansal P, Goyal H. COVID-19 presenting as acute pancreatitis. Pancreatology 2020;20:1026-1027.

57. Aziz M, Perisetti A, Lee-Smith WM, Gajendran M, Bansal P, Goyal H. Taste changes (Dysgeusia) in COVID-19: a systematic review and metaanalysis. Gastroenterology 2020;159:1132-1133.

58. Perisetti A, Gajendran M, Boregowda U, Bansal P, Goyal H. COVID-19 and gastrointestinal endoscopies: current insights and emergent strategies. Dig Endosc 2020 Apr 13 [Online ahead of print]. doi: 10.1111/den.13693.

59. Perisetti A, Gajendran M, Goyal H. Putative mechanisms of diarrhea in COVID-19. Clin Gastroenterol Hepatol 2020 Jun 12 [Online ahead of print]. doi: 10.1016/j.cgh.2020.06.008.

60. Wang D, Hu B, Hu C, et al. Clinical characteristics of 138 hospitalized patients with 2019 novel coronavirus-infected pneumonia in Wuhan, China. JAMA 2020;323:1061-1069.

61. Wong SH, Lui RN, Sung JJ. Covid-19 and the digestive system. J Gastroenterol Hepatol 2020;35:744-748.

62. Zhang JJ, Dong X, Cao YY, et al. Clinical characteristics of 140 patients infected with SARS-CoV-2 in Wuhan, China. Allergy 2020;75:1730-1741.

63. Iacucci M, Cannatelli R, Labarile N, et al. Endoscopy in inflammatory bowel diseases during the COVID-19 pandemic and post-pandemic period. Lancet Gastroenterol Hepatol 2020;5:598-606.

64. Ramachandran P, Onukogu I, Ghanta S, et al. Gastrointestinal symptoms and outcomes in hospitalized coronavirus disease 2019 patients. Dig Dis 2020;38:373-379.

65. Ramachandran P, Gajendran M, Perisetti A, et al. Red blood cell distribution width (RDW) in hospitalized COVID-19 patients. medRxiv 2020. doi: 10.1101/2020.06.29.20143081

66. IOIBD update on COVID19 for patients with Crohn's disease and ulcerative colitis. Available from: https://www.ioibd.org/ ioibd-update-on-covid19-for-patients-with-crohns-disease-andulcerative-colitis/

67. Rubin DT, Feuerstein JD, Wang AY, Cohen RD. AGA clinical practice update on management of inflammatory bowel disease during the covid-19 pandemic: expert commentary. Gastroenterology 2020;159:350-357.

68. Rubin LG, Levin MJ, Ljungman P, et al. 2013 IDSA clinical practice guideline for vaccination of the immunocompromised host. Clin Infect Dis 2014;58: 309-318.

69. Goulding NJ. The molecular complexity of glucocorticoid actions in inflammation - a four-ring circus. Curr Opin Pharmacol 2004;4:629-636.

70. Neurath MF. COVID-19 and immunomodulation in IBD. Gut 2020;69:1335-1342.

71. Wu C, Chen X, Cai Y, et al. Risk factors associated with acute respiratory distress syndrome and death in patients with coronavirus disease 2019 pneumonia in Wuhan, China. JAMA Intern Med 2020;180:934-943.

72. Azathioprine. Immunotherapy in Transplantation. pp. 171-181

73. Bleyer WA. The clinical pharmacology of methotrexate: new applications of an old drug. Cancer 1978;41:36-51.

74. Algood HM, Lin PL, Flynn JL. Tumor necrosis factor and chemokine interactions in the formation and maintenance of granulomas in tuberculosis. Clin Infect Dis 2005;41 Suppl 3:S189-S193.

75. Kaneko H, Yamada H, Mizuno S, et al. Role of tumor necrosis factoralpha in Mycobacterium-induced granuloma formation in tumor necrosis factor-alpha-deficient mice. Lab Invest 1999;79:379-386.

76. Burgueño JF, Reich A, Hazime H, et al. Expression of SARS-CoV-2 entry molecules ACE2 and TMPRSS2 in the gut of patients with IBD. Inflamm Bowel Dis 2020;26:797-808.

77. Stebbing J, Phelan A, Griffin I, et al. COVID-19: combining antiviral and anti-inflammatory treatments. Lancet Infect Dis 2020;20:400-402. 
78. Tocilizumab vs CRRT in management of cytokine release syndrome (CRS) in COVID-19 (TACOS). Available from: https:// clinicaltrials.gov/ct2/show/NCT04306705

79. Haberman R, Axelrad J, Chen A, et al. Covid-19 in immunemediated inflammatory diseases - case series from New York. $N$ Engl J Med 2020;383:85-88.

80. Xeljanz, Xeljanz XR (tofacitinib): Drug safety communication due to an increased risk of blood clots and death with higher dose. Available from: https://www.fda.gov/safety/medical-productsafety-information/xeljanz-xeljanz-xr-tofacitinib-drug-safetycommunication-due-increased-risk-blood-clots-and-death

81. Klok FA, Kruip MJHA, van der Meer NJM, et al. Incidence of thrombotic complications in critically ill ICU patients with COVID-19. Thromb Res 2020;191:145-147.

82. Boyman O, Sprent J. The role of interleukin-2 during homeostasis and activation of the immune system. Nat Rev Immunol 2012;12:180-190.

83. Di Lernia V, Goldust M, Feliciani C. Covid-19 infection in psoriasis patients treated with cyclosporin. Dermatol Ther 2020;1:e13739.

84. BSG expanded consensus advice for the management of IBD during the COVID-19 pandemic. Available from: https://www.bsg.org.uk/ covid-19-advice/bsg-advice-for-management-of-inflammatorybowel-diseases-during-the-covid-19-pandemic

85. COVID-19 AND IBD. Available from: https://crohnsandcolitis.ca/ covid19

86. COVID-19 ECCO Task Force. Available from: https://www.eccoibd.eu/publications/covid-19.html. Accessed on June 14, 2020.

87. An P, Ji M, Ren H, et al. Protection of 318 inflammatory bowel disease patients from the outbreak and rapid spread of COVID-19 infection in Wuhan, China. 2020. Available from: https://ssrn.com/ abstract=3543590 or http://dx.doi.org/10.2139/ssrn.3543590

88. Rubin DT, Abreu MT, Rai V, Siegel CA; International Organization for the Study of Inflammatory Bowel Disease. Management of patients with Crohn's disease and ulcerative colitis during the coronavirus disease-2019 pandemic: results of an international meeting. Gastroenterology 2020;159:6-13.

89. Green K, Graziadio S, Turner P, Fanshawe T, Allen J. Molecular and antibody point-of-care tests to support the screening, diagnosis and monitoring of COVID-19. Oxford COVID-19 Evidence Service 2020. https://4allofus.org.uk/wp-content/uploads/2020/04/POCTCovid19.pdf [Epub ahead of print].

90. Stockman LJ, Bellamy R, Garner P. SARS: systematic review of treatment effects. PLoS Med 2006;3:e343.

91. Russell CD, Millar JE, Baillie JK. Clinical evidence does not support corticosteroid treatment for $2019-\mathrm{nCoV}$ lung injury. Lancet 2020;395:473-475.
92. Lee N, Allen Chan KC, Hui DS, et al. Effects of early corticosteroid treatment on plasma SARS-associated Coronavirus RNA concentrations in adult patients. J Clin Virol 2004;31:304-309.

93. Arabi YM, Mandourah Y, Al-Hameed F, et al; Saudi Critical Care Trial Group. Corticosteroid therapy for critically ill patients with Middle East respiratory syndrome. Am J Respir Crit Care Med 2018;197:757-767.

94. Lamb CA, Kennedy NA, Raine T, et al; IBD guidelines eDelphi consensus group. British Society of Gastroenterology consensus guidelines on the management of inflammatory bowel disease in adults. Gut 2019;68:s1-s106.

95. Din S, Kent A, Pollok RC, et al. Adaptations to the British Society of Gastroenterology guidelines on the management of acute severe UC in the context of the COVID-19 pandemic: a RAND appropriateness panel. Gut 2020;69:1769-1777.

96. Horby P, Lim WS, Emberson JR, et al. Dexamethasone in hospitalized patients with Covid-19-preliminary report. $\mathrm{N}$ Engl J Med 2020 Jul 17 [Online ahead of print]. doi: 10.1056/ NEJMoa2021436

97. Gajendran $M$, Loganathan P, Jimenez G, et al. A comprehensive review and update on ulcerative colitis. Dis Mon 2019;65:100851.

98. Meikle AW, Tyler FH. Potency and duration of action of glucocorticoids: effects of hydrocortisone, prednisone and dexamethasone on human pituitary-adrenal function. Am J Med 1977;63:200-207.

99. Gastroenterology professional society guidance on endoscopic procedures during the COVID-19 pandemic. Available from: https://www.gastro.org/practice-guidance/practice-updates/ covid-19/gastroenterology-professional-society-guidance-onendoscopic-procedures-during-the-covid-19-pandemic

100. Sultan S, Lim JK, Altayar O, et al; AGA Institute. Electronic address: ewilson@gastro.org. AGA Rapid Recommendations for Gastrointestinal Procedures During the COVID-19 Pandemic. Gastroenterology 2020;159:739-758.

101. Wu YC, Chen CS, Chan YJ. The outbreak of COVID-19: An overview. J Chin Med Assoc 2020;83:217-220.

102. Wu Z, McGoogan JM. Characteristics of and important lessons from the Coronavirus disease 2019 (COVID-19) outbreak in China: summary of a report of 72314 cases from the Chinese Center for disease control and prevention. JAMA 2020;323:1239-1242.

103. Liang W, Guan W, Chen R, et al. Cancer patients in SARSCoV-2 infection: a nationwide analysis in China. Lancet Oncol 2020;21:335-337. 